\title{
Biosynthetic Origin of Graphenone in Cultured Lichen Mycobionts of Graphis handelii
}

\author{
Yukiko Takenaka ${ }^{\mathrm{a}}$, Nobuo Hamada ${ }^{\mathrm{b}}$, and Takao Tanahashi ${ }^{\mathrm{a}, *}$ \\ a Kobe Pharmaceutical University, 4-19-1, Motoyamakita-machi, Higashinada-ku, \\ Kobe 658-8558, Japan. Fax: +81-78-441-7545. E-mail: tanahash@kobepharma-u.ac.jp \\ b Osaka City Institute of Public Health and Environmental Sciences, 8-34, Tojo-cho, \\ Tennouji-ku, Osaka 543-0026, Japan \\ * Author for correspondence and reprint requests \\ Z. Naturforsch. 63c, 565-568 (2008); received February 5, 2008
}

The biosynthetic origins of the carbon skeleton in graphenone were verified by feeding the culture of spore-derived mycobionts of the lichen Graphis handelii with sodium $\left[1-{ }^{13} \mathrm{C}\right]-$ acetate, sodium $\left[1,2-{ }^{13} \mathrm{C}_{2}\right]$-acetate, sodium $\left[2-{ }^{13} \mathrm{C}\right]$-pyruvate, $\left[1,2,3-{ }^{13} \mathrm{C}\right]$-glycerol, $\left[{ }^{13} \mathrm{CH}_{3}\right]-$ methionine and sodium $\left[1,4-{ }^{13} \mathrm{C}_{2}\right]$-succinate.

Key words: Graphis handelii, Isolated Lichen Mycobiont, Graphenone

\section{Introduction}

Lichens are symbiotic organisms comprised of a fungus, mycobiont, and a photosynthetic partner, photobiont, which may be a cyanobacterium and/ or green alga. They produce characteristic secondary metabolites, i.e. lichen substances. An intriguing question concerning the formation of the lichen substances is the role of mycobiont and photobiont partners in the biosynthesis of these substances. Our recent studies demonstrated that cultures of lichen mycobionts isolated from the apothecia have an ability to produce diverse substances. For instance, $6 H$-dibenzo $[b, d]$ pyran-6-one derivatives (Tanahashi et al., 1997, 2003) and graphenone (Miyagawa et al., 1994) have been obtained from the cultured lichen mycobionts of Graphis species. These compounds have never been detected in the lichenized state but are structurally related to metabolites found in fungi. Thus, cultures of lichen mycobionts could be good tools for investigating the potential ability of the fungal partner in secondary metabolism. According to our interest in the relationship between symbiosis and metabolism of lichen, the biogenetic origin of the carbon skeleton in graphenone was investigated and compared with the fungal metabolism.

\section{Materials and Methods}

\section{General experimental procedures}

The NMR experiments were performed with a Varian VXR-500 spectrometer using tetramethyl- silane as an internal standard. Thin-layer chromatography was performed on pre-coated Kieselgel 60F254 plates (Merck), and spots were visualized under UV light.

\section{Plant material}

Specimens of Graphis handelii Zahlbr. were collected from the bark of cherry (Prunus yedoensis) in Minakuchi-cho, Shiga Prefecture, Japan (80 m altitude) in November 1998. The voucher specimen was identified by Prof. M. Nakanishi, Hiroshima University, Japan and was deposited at Osaka City Institute of Public Health and Environmental Sciences, Japan (registration No. NH9811086). Mycobionts of G. handelii were obtained from the spores discharged from apothecia of a thallus, and were cultivated in test tubes containing modified MY10 medium (10 g malt extract, $4 \mathrm{~g}$ yeast extract, $100 \mathrm{~g}$ sucrose, $15 \mathrm{~g}$ agar, $11 \mathrm{H}_{2} \mathrm{O}$, $\mathrm{pH} 7$ ) at $18{ }^{\circ} \mathrm{C}$ in the dark. After cultivation for 11-12 months, the colonies and slants with crystals were harvested. The harvested colonies were extracted and worked-up in the usual way to isolate graphenone, which was identified by comparison with an authentic sample (Hamada et al., 2001).

\section{Chemicals}

${ }^{13} \mathrm{C}$-Labeled compounds (99\% enriched) were obtained from Sigma-Aldrich Fine Chemicals, St. Louis, USA. 
Feeding experiments with labeled precursors

(a) Feeding of sodium $\left[1-{ }^{13} \mathrm{C}\right]$-acetate (Exp. 1) and sodium $\left[1,2-{ }^{13} \mathrm{C}_{2}\right]$-acetate (Exp. 2). Cultured mycobionts of $G$. handelii were transferred to test tubes containing modified MY5 medium (10 g malt extract, $4 \mathrm{~g}$ yeast extract, $50 \mathrm{~g}$ sucrose, $15 \mathrm{~g}$ agar, $\left.11 \mathrm{H}_{2} \mathrm{O}, \mathrm{pH} 7\right)(10 \mathrm{ml} /$ tube $)$ and supplemented with each labeled substrate ( $25 \mathrm{mg} / \mathrm{tube})$. The cultures were grown at $18^{\circ} \mathrm{C}$ in the dark for 2 months. After addition of labeled substrate (20 mg/tube), the cultures were grown for further 5 months. The colonies (Exp. 1: dry weight $1.92 \mathrm{~g} /$ 16 test tubes; Exp. 2: dry weight $1.54 \mathrm{~g} / 15$ test tubes) were harvested and extracted with $\mathrm{Et}_{2} \mathrm{O}$. The $\mathrm{Et}_{2} \mathrm{O}$ extract was purified by preparative TLC with toluene/acetone $(4: 1)$ to give 1 (Exp. 1: $12.6 \mathrm{mg}$; Exp. 2: $11.6 \mathrm{mg}$ ).

(b) Feeding of sodium $\left[2-{ }^{13} \mathrm{C}\right]$-pyruvate (Exp. 3) or $\left[1,2,3-{ }^{13} \mathrm{C}_{3}\right]$-glycerol (Exp. 4). Sodium $\left[2-{ }^{13} \mathrm{C}\right]-$ pyruvate $(5 \mathrm{mg} /$ tube $)$ or $\left[1,2,3-{ }^{13} \mathrm{C}_{3}\right]$-glycerol ( $5 \mathrm{mg} /$ tube) was administered to the cultures (each 10 test tubes) grown on MY10 medium in the same way as in Exp. 1. After cultivation at $18^{\circ} \mathrm{C}$ in the dark for 2 months, sodium $\left[2-{ }^{13} \mathrm{C}\right]$-pyruvate (5 mg/tube) or $\left[1,2,3-{ }^{13} \mathrm{C}_{3}\right]$-glycerol (10 mg/tube) was added to the cultures, which were grown for further 4 months. The colonies (Exp. 3: dry weight 1.47 g/10 test tubes; Exp. 4: dry weight $1.00 \mathrm{~g} / 10$ test tubes) were worked-up to afford 1 (Exp. 3: $12.6 \mathrm{mg}$; Exp. 4: $11.6 \mathrm{mg}$ ).

(c) Feeding of $\left[{ }^{13} \mathrm{CH}_{3}\right]$-methionine (Exp. 5). L- $\left[{ }^{13} \mathrm{CH}_{3}\right]$-Methionine (25 $\mathrm{mg} /$ tube) was added to the cultures ( 9 test tubes), which were grown at $18^{\circ} \mathrm{C}$ in the dark for 7 months. The colonies (dry weight $0.95 \mathrm{~g}$ ) were worked-up to afford $\mathbf{1}$ (11.7 mg).

(d) Feeding of sodium $\left[1,4-{ }^{13} \mathrm{C}_{2}\right]$-succinate. The feeding experiment with sodium $\left[1,4-{ }^{13} \mathrm{C}_{2}\right]$-succinate $(10 \mathrm{mg} /$ tube, 10 test tubes) was performed. The colonies (dry weight $2.55 \mathrm{~g}$ ) were worked-up to afford 1 (19.1 $\mathrm{mg})$

\section{Results}

Graphenone is a metabolite isolated from the cultured mycobionts of Graphis scripta (Miyagawa et al., 1994) but is structurally similar to itaconitin, a fungal metabolite from Aspergillus itaconicus Kinoshita (Fig. 1). The biosynthetic studies on itaconitin demonstrated that the $\mathrm{C}_{10}$-chain and the methyl carbon atom derived from acetate-malonate and a $\mathrm{C}_{1}$-unit, and the $\mathrm{C}_{3}$-unit was probably<smiles>CC(=O)/C(C)=C/C=C/C=C/C1=C(C)C(=O)OC1=O</smiles><smiles>CC1=C(/C=C/C=C/C=C(\C)CC(=O)O)C(=O)OC1=O</smiles>

Itaconitin<smiles>CCCCCC=C(C(=O)O)C(C)C(=O)O</smiles>

Piliformic acid

Fig. 1. Chemical structures of graphenone and related compounds.

introduced from phosphoenolpyruvate (PEP) or oxaloacetate which is formed by the carboxylation of PEP (Sankawa and Shibata, 1969). Assuming a parallel biosynthetic pathway is followed in the case that graphenone could be formed from a $\mathrm{C}_{10^{-}}$ chain, $\mathrm{C}_{1}$-unit and $\mathrm{C}_{3}$-unit. The $\mathrm{C}_{10}$-chain derived from head-to-tail linkage of six acetate units should condense with a $\mathrm{C}_{3}$-unit. To gain further insight into the origin of the $\mathrm{C}_{3}$-unit, feeding experiments with the ${ }^{13} \mathrm{C}$-labelled pyruvate, glycerol and succinate were undertaken.

For feeding experiments, specimens of Graphis handelii were newly collected and their spore-derived mycobionts were cultivated, since the preliminary screening demonstrated that graphenone was produced in the cultured mycobionts of $G$. handelii (Hamada et al., 2001). After cultivation, the harvested colonies were extracted. The extracts were separated by a combination of $\mathrm{CC}$, preparative TLC and/or preparative HPLC, to afford graphenone, confirming the preliminary screening by TLC (Hamada et al., 2001).

Incorporation of sodium [1-13 C]-acetate and sodium $\left[1,2-{ }^{13} C_{2}\right]$-acetate into graphenone

In the proton-noise-decoupled ${ }^{13} \mathrm{C}$ NMR spectrum of graphenone isolated from the culture grown on medium containing sodium $\left[1-{ }^{13} \mathrm{C}\right]$-acetate, carbon atoms 4, 1', 3', 5', 7' were enriched 


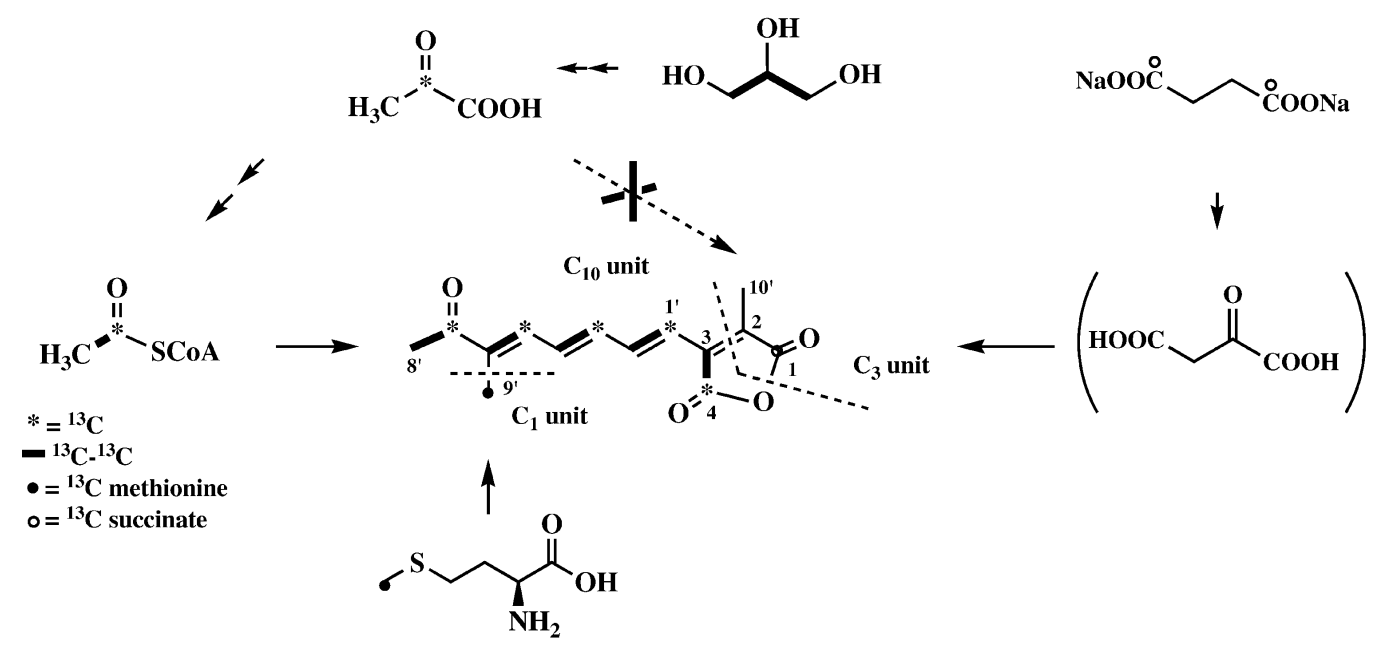

Fig. 2. Biosynthetic origin of graphenone.

relative to the natural abundance spectrum. On the other hand, carbon atoms 1,2 , and $10^{\prime}$ showed no incorporation. The INADEQUATE (incredible natural abundance double quantum transfer experiment) spectrum of the $\left[1,2-{ }^{13} \mathrm{C}_{2}\right]$-acetate-enriched graphenone showed five pairs of ${ }^{13} \mathrm{C}-{ }^{13} \mathrm{C}$ couplings, indicating that carbon atoms s 3 and 4 , $1^{\prime}$ and $2^{\prime}, 3^{\prime}$ and $4^{\prime}, 5^{\prime}$ and $6^{\prime}$, and $7^{\prime}$ and $8^{\prime}$ originate from intact acetate units. The feeding experiments with labeled acetates demonstrated that a $\mathrm{C}_{10}$ moiety (C-4-3, C-1'-8') was derived from five acetate units via the acetate-malonate pathway as recognized in the biosynthetic study of itaconitin (Sankawa and Shibata, 1969).

Incorporation of sodium $\left[2{ }^{13} \mathrm{C}\right]$-pyruvate and $\left[1,2,3-{ }^{13} C_{3}\right]$-glycerol into graphenone

On feeding of sodium $\left[2-{ }^{13} \mathrm{C}\right]$-pyruvate and $\left[1,2,3-{ }^{13} \mathrm{C}_{3}\right]$-glycerol, the ${ }^{13} \mathrm{C}$ NMR spectra of graphenone revealed the same labeling pattern as encountered in the sodium $\left[1-{ }^{13} \mathrm{C}\right]$-acetate or $[1,2-$ ${ }^{13} \mathrm{C}_{2}$ ]-acetate feeding experiments. These results can be rationalized by biological degradation of pyruvate and glycerol into acetate. No incorporation of pyruvate and glycerol to a $\mathrm{C}_{3}$-unit led us to exclude the possibility that pyruvate was involved in the biosynthesis of graphenone.

Incorporation of sodium $\left[1,4-{ }^{13} C_{2}\right]$-succinate and ${ }_{L}-\left[{ }^{13} \mathrm{CH}_{3}\right]$-methionine into graphenone

On feeding experiments with sodium $\left[1,4-{ }^{13} \mathrm{C}_{2}\right]-$ succinate and $\mathrm{L}_{-}\left[{ }^{13} \mathrm{CH}_{3}\right]$-methionine, the ${ }^{13} \mathrm{C}$ NMR spectra of graphenone showed significant enhancements at C-1 and C-9', respectively.

The feeding experiments with labeled methionine showed that the origin of the methyl carbon atom C-9' was $S$-adenosylmethionine. Efficient incorporation of sodium succinate into the C-1 carbonyl group suggested that condensation of two sub-units required for the graphenone biosynthesis occurred between a $\mathrm{C}_{10}$-fatty acid and a $\mathrm{C}_{4}$ citric acid cycle intermediate rather than pyruvate. The most likely candidate for the $\mathrm{C}_{4}$-intermediate is oxaloacetate.

\section{Discussion}

Feeding of sodium $\left[1-{ }^{13} \mathrm{C}\right]$-acetate and [1,2${ }^{13} \mathrm{C}_{2}$ ]-acetate resulted in moderate incorporation into the $\mathrm{C}_{10}$-chain of graphenone in the manner as expected for the metabolism of fatty acids. The experiment showed the expected result that the C$9^{\prime}$ methyl group originates from methionine. Further experiments with sodium $\left[2-{ }^{13} \mathrm{C}\right]$-pyruvate, $\left[1,2,3-{ }^{13} \mathrm{C}_{3}\right]$-glycerol, and sodium $\left[1,4-{ }^{13} \mathrm{C}_{2}\right]$-succinate led to the conclusion that the $\mathrm{C}_{3}$-unit was derived from the $\mathrm{C}_{4}$-intermediate, but not from any possible $\mathrm{C}_{3}$ candidate. These observations demonstrated that a $\mathrm{C}_{10}$-fatty acid was condensed with a $\mathrm{C}_{4}$-unit in the biosynthesis of graphenone. This is the case for piliformic acid, which is a fungal metabolite of Poronia piliformis (Chesters and O'Hagan, 1997). These results illustrated in Fig. 2 implied that the metabolism induced in the cultures of the isolated mycobionts of Graphis handelii was 
closely similar to that of free-living fungi. From the view-point of evolution, the origin of isolated mycobionts might be the same as that of any freeliving fungus, and they were separated in the evolutional process (Lutzoni et al., 2001). In symbiotic state with photobionts, the mycobionts might conserve the original metabolic ability of ancient mycobionts. These metabolic pathways might be normally suppressed by any action of the photobiont, but expressed in the isolated mycobiont.

Bloomer J. L., Eder W. R., and Hoffman W. F. (1968), The biosynthesis of (+)-protolichesterinic acid. Chem. Comm., 354-355.

Chesters N. C. J. E. and O'Hagan D. (1997), Biosynthesis of the fungal metabolite, piliformic acid (2-hexylidene-3-methylsuccinic acid). J. Chem. Soc. Perkin Trans. 1, 827-834.

Hamada N., Tanahashi T., Miyagawa H., and Miyawaki H. (2001), Characteristics of secondary metabolites from isolated lichen mycobionts. Symbiosis 31, 23-33.

Lutzoni F., Pagel M., and Reeb V. (2001), Major fungal lineages are derived from lichen symbiotic ancestors. Nature 411, 937-940.

Miyagawa H., Hamada N., Sato M., and Ueno T. (1994), Pigments from the cultured lichen mycobionts of Gra-

\section{Acknowledgements}

We are grateful to former Prof. M. Nakanishi (Hiroshima University, Japan) for identification of the voucher specimen. Thanks are also due to Dr. M. Sugiura (Kobe Pharmaceutical University, Japan) for NMR measurements. This research was financially supported in part by Grants-in-Aid for Scientific Research (C) (No. 09672179 and No. 11672129) from the Ministry of Education, Sciences, Sports and Culture of Japan and Kobe Pharmaceutical University Collaboration Fund.

phis scripta and G. desquamescens. Phytochemistry 36, 1319-1322.

Sankawa U. and Shibata S. (1969), Biosynthesis of natural products. V. Biosynthesis of itaconitin. (2). Tracer studies on itaconitin. Chem. Pharm. Bull. 17, 20252030.

Tanahashi T., Kuroishi M., Kuwahara A., Nagakura N., and Hamada N. (1997), Four phenolics from the cultured lichen mycobiont of Graphis scripta var. pulverulenta. Chem. Pharm. Bull. 45, 1183-1185.

Tanahashi T., Takenaka Y., Nagakura N., and Hamada N. (2003), 6H-Dibenzo[b,d]pyran-6-one derivatives from the cultured lichen mycobionts of Graphis spp. and their biosynthetic origin. Phytochemistry 62, 7175 . 